\section{Questión}

Periodismo / Comunicación ISSN 1669-6581

El eterno resplandor de la radio en el cine

Diego Martín Díaz

Question/Cuestión, Vol. 2, № 66, Agosto 2020

ISSN 1669-6581

https://perio.unlp.edu.ar/ojs/index.php/question/index

IICom-FPyCS-UNLP

\title{
EL ETERNO RESPLANDOR DE LA RADIO EN EL CINE
}

\section{THE ETERNAL RADIANCE OF RADIO IN THE CINEMA}

Diego Martín Díaz

admdiaz@yahoo.com.ar

Docente-Investigador Facultad de Periodismo y Comunicación Social

Estudió guion cinematográfico en la ENERC (Escuela Nacional de Experimentación y Realización Cinematográfica)

Universidad Nacional de La Plata Colaboración: Juan Manuel Rada, Emanuel de la Fuente

\section{Palabras Clave}

Radio, Cine, Tiempo

\section{Keywords}

Radio, Cinema, Time 
Si te preguntan por alguna película sobre la radio tu respuesta dependerá de la edad que tengas. Los 80's tal vez hayan sido marcados por Solos en la madrugada. Quienes fueron jóvenes en los 90 tal vez recuerden mejor Días de Radio o Good Morning Vietnam. O por qué no la rebelde Suban el Volumen. Un poco más acá en el tiempo tal vez puede parecer que la única película sobre la radio fue The Boat That Rocked. En fin, películas sobre la radio hay muchas y hubo en todos los tiempos. Pero también hay otras que sin ser específicamente sobre la radio la muestran en sus aspectos más atractivos y reveladores. Acá un repaso de algunas.

"Sería una buena idea que dejara la radio encendida todo el tiempo,

Ms. Torrance."

La advertencia de un oficial de policía se anuncia, a la distancia y por radio transistor, casi como una premonición y resuena en las paredes del misterioso y desolado hotel Overlook. Puede ser una escena intrascendente de El Resplandor (Stanley Kubrick, 1980) pero traza una metáfora maravillosa sobre la radio.

Los Torrance están solos en la inmensidad de un hotel anclado en lo alto de una montaña, alejados de cualquier centro urbano. Una tormenta de nieve amenaza con aislarlos aún más. Y la radio se impone allí como único nexo. Mantener la radio encendida aparece como un consejo o mandato para desafiar el aislamiento y el peligro y sostener la conexión. Estar en contacto pese a todo. 
Es difícil pensar que El Resplandor sea una película sobre la radio. Nadie la pondría en una lista de estas características. Pero hay un aspecto de la historia en la que la radio, en tanto posibilidad de conexión a distancia, juega su papel. Es la dimensión técnica y a la vez primaria de la radio como dispositivo: conectarnos superando la distancia física.

Hasta los fantasmas que habitan el hotel Overlook perecen tener conciencia de este poder y alcance de la radio. Algunos minutos más tarde, con el hotel completamente aislado y el vínculo familiar roto, el Sr. Torrance es desafiado por uno de los fantasmas del hotel para que asesine a su familia. Lo primero que hace, como parte del plan, es desmantelar el radio transistor y acabar con toda posibilidad de contacto con el exterior.

Sin la radio, sin la posibilidad de ese contacto con alguien que está en otro espacio y puede escuchar y socorrer, se impone un mundo en el que sólo resta valernos de nosotros mismos frente a los peligros de la vida real y la vida fantasmagórica.

Con hombres desequilibrados y fantasmas conscientes del poder de la radio se construye una metáfora maravillosa. Porque en El resplandor, finalmente, terminan conectados dos polos opuestos que siempre aparecen asociados en las representaciones que como sociedad nos hacemos de la radio: su posibilidad técnica del alcance a distancia con su dimensión mágica, que también está anclada en el alcance a distancia produce.

Tenemos aquí una primera representación de la radio asociada más bien a la posibilidad técnica del dispositivo: la explotación del espectro de ondas electromagnéticas que hacen posible la transmisión de mensajes a distancia. Es volver a los orígenes mismos de la radio cuando todavía no era ese medio 
de comunicación e institución social consagrada bajo las coordenadas que se impusieron durante el siglo XX.

La radio siempre nos remite a este origen, allí radica todavía hoy su potencia. $Y$ en esta clave también es posible entender más cabalmente porque Marshall McLuhan denominó a la radio "el tambor tribal" en su clásico libro Comprender a los medios de comunicación. Allí el profeta del nuevo orden tecnológico explicaba:

"La radio afecta a la gente de una forma muy íntima, de tú a tú, y ofrece todo un mundo de comunicación silenciosa (...) Éste es el aspecto inmediato de la radio. Una experiencia íntima. Las profundidades subliminales de la radio están cargadas de los ecos retumbantes de los cuernos tribales y de los antiguos tambores." (McLuhan, 1964)

"No me digas cómo seducir al electorado, no iremos de uno por uno, nos comunicaremos con las masas."

De este modo, el gobernador de Mississipi que está en busca de su reelección da un sermón a uno de sus asesores de campaña en las puertas de WEZY, una pequeña radio ubicada en el medio de la nada.

La escena pertenece a ¿Dónde estás hermano? (Joel y Ethan Coen, 2000), otra película que probablemente tampoco ubicaríamos en un listado específico sobre la radio, pero donde sin embargo el medio de comunicación es clave en el giro principal de la trama.

Estamos en 1937, en el sur de los Estados Unidos. Tres hombres recién fugados de la cárcel dan un aventón en su auto robado a un guitarrista. El hombre viaja camino a WEZY, una estación de radio donde el dueño paga buen dinero a los músicos que tocan en vivo en sus emisiones. 
Probablemente pocas imágenes sinteticen de manera tan pregnante y eficaz el poder de la radio como la que se produce en la escena en la que estos cuatro hombres llegan a WEZY. En medio de un ámbito rural inhóspito y completamente desolado se erige una pequeña y humilde casa blanca con una típica antena de emisora radial. WEZY está en el medio de la nada, pero pronto descubriremos que eso no le impide meterse en la vida de todas y todos con notable éxito.

Dentro de la radio los cuatro hombres simulan ser un grupo de música y tocan de manera improvisada una canción folclórica. Reciben la paga y siguen su camino. Al salir de la emisora se cruzan con Menelaus "Pappy" O'Daniel, el gobernador de Mississippi y su equipo de campaña que también vienen a hacer uso del medio.

Este cruce es un paréntesis en la trama, pero el intercambio es muy pintoresco para pensar la radio como medio y mediación desde una perspectiva política. Los asesores de campaña piden al gobernador que se acerque a saludar a estos cuatro hombres que acaban de salir de la radio. Pero "Pappy desprecia la posibilidad de ese intercambio porque apuesta a algo mejor: llegar a la gente a través de la radio y así conquistar a las masas.

Una interesante vuelta para pensar la radio y sus modos de representación a través del tiempo. Incluso sobre la base de esa conexión íntima la radio desarrolló rápida y eficazmente un poder de alcance masivo que ha sido largamente estudiado. McLuhan llegó incluso a atribuir la existencia de Hitler a los efectos de la radio sobre las sociedades alfabetizadas: 
"Que Hitler llegara a existir políticamente se debe directamente a la radio y a los sistemas de megafonía. Ello no quiere decir que estos medios transmitieron eficazmente sus pensamientos al pueblo alemán. Poco importaban sus pensamientos. La radio brindó la primera experiencia multitudinaria de implosión electrónica, ese cambio de dirección y de sentido de toda la civilización alfabetizada occidental." (McLuhan, 1964)

En ¿Dónde estás hermano? la radio es representada en relación con esta posibilidad de escucha colectiva y comunitaria. La política o el arte impactan masivamente en las comunidades y las personas a partir de la capacidad de transmisión masiva que la radio habilita. La sentencia profética del gobernador Pappy para pensar la relación entre política la radio y las masas, termina refrendándose en el argumento principal de la política.

Esa canción que los The Soggy Bottom Boys (este es el nombre improvisado que le ponen al grupo) graban como al pasar en WEZY termina convirtiéndose en un éxito popular gracias a la difusión en la radio. Pero nadie conoce los rostros de quienes cantan la canción, y los intérpretes transcurren toda la película sin ser conscientes del éxito que (no) están protagonizando.

Sobre el final de la película hay una secuencia donde la verdad se revela. En una fiesta de club de pueblo, otra vez por casualidad The Soggy Bottom Boys suben a tocar al escenario y tras los primeros acordes de su canción todo el público reacciona al reconocerlos. Los rostros de las personas transmiten alegría y asombro, y a la vez cierta familiaridad con lo que ven. Ese grupo de músicos que nunca antes habían visto les resulta muy cercano y es porque los han escuchado mucho a través de la radio. 
La radio y la música se conjugan en esta película para construir la ecuación de un poder supremo que logra, incluso, revertir el curso de una tendencia política. El gobernador, presente en aquel evento, rápidamente reconoce la popularidad de estos "desconocidos" y se monta sobre ellos para derrotar a su contrincante. Sobre el final de la secuencia se advierte además que todo lo que está sucediendo en el club está siendo transmitido por radio y llega al espacio íntimos de las vecinas y vecinos que no pueden estar físicamente en la celebración.

En algún sentido ¿Dónde estás hermano? es toda una representación visual sobre la construcción de un fenómeno cultural popular / masivo mediado por la radio. En el balance del film y pensando estrictamente en el lugar de la radio, resulta muy revelador el contraste de esa primer imagen de la radio, solitaria en medio de un páramo, con los alcances y efectos a gran escala que logra lo que a través de ella se transmite.

También Mc Luhan había advertido sobre esta cuestión en relación a la radio, esa capacidad insospechada, y muchas veces inadvertida, que la radio tiene para instalarse en el seno de nuestras vidas particulares permitiéndonos formar parte de una especie de comunidad imaginada:

"Como todo medio, la radio tiene su manto de invisibilidad. Nos llega manifiestamente con una franqueza de tú a tú, particular e íntima, cuando en realidad se trata de una cámara de resonancia del poder mágico de tocar acordes remotos y olvidados." (McLuhan, 1964) iii $^{\mathrm{i}}$

“¿Está la nación lista para dos minutos de silencio de radio?” Hablando de las comunidades imaginadas que la radio crea y recrea, tenemos también la historia de un rey atribulado por las tensiones entre la exigente 
exposición pública y su defecto en el habla. Hablamos de Jorge VI de Inglaterra y el retrato de un aspecto de su vida que aparece en El discurso del rey (Tom Hooper, 2010).

Para quienes aman el cine y la radio la secuencia inicial de esta película es imperdible: montaje rápido de una serie de gestos minúsculos componen un relato que da cuenta de los preparativos para una transmisión radiofónica en vivo. Aparece allí, con notable perfección visual, la radio como medio: sus dispositivos, sus personajes, sus ritos, sus espacios, sus tiempos, y hasta los saberes construidos en torno a una práctica moderna. En medio de ese universo fantástico un hombre de radio intenta calmar los nervios del entonces duque de York, más tarde Rey Jorge VI, antes de salir al aire: el micrófono hará su trabajo.

¿Hace realmente el micrófono su trabajo? Este Rey es tartamudo y eso es un problema para su condición pero también para el uso que hace de la radio en tanto su principal medio de comunicación con el pueblo. En esta conjunción aparece unos de los aspectos más interesantes para observar de la película: la radio aparece como el espacio privilegiado y naturalizado de comunicación más directa (efectiva y afectiva) entre el rey y sus súbditos. Una compleja combinación que rápidamente será tradición. Esta posibilidad de comunicación a través de la radio está inscripta en la propia concepción del poder.

De aquí emerge esa pregunta incómoda que el Rey hace en un momento a su terapeuta Lionel Logue: “¿Está la nación lista para dos minutos de silencio de radio?" La pregunta es una síntesis brutal que propone conjugar una reflexión entre comunicación y política. Porque en la caracterización de este personaje que se describe en el film no sólo aparece la frustración individual sino una 
revelación inquietante sobre los modos del poder para hacer uso de la comunicación de masas en el proceso de construcción de una nación.

Centrada en la dificultad en el habla del Rey y la exigencia de una disertación pública fluida como camino, la película construye una trama que nos conduce, como espectadores, por un camino en el que olvidamos preguntarnos algo fundamental: ¿que tiene para decir este Rey y por qué es tan importante que lo diga bien? Sólo al final será posible descubrirlo.

$Y$ esto es porque lo que está en juego no es algo que tenga que ver con la información que hay para comunicar sino los modos de la construcción de un discurso. Esto conduce a pensar en algo muy interesante que aparece en El discurso del Rey que está íntimamente relacionado con la radio: la empatía. ¿Qué necesita este Rey? Construir empatía. Para eso tiene a la radio. Pero tiene un terrible obstáculo: su tartamudez.

La secuencia final está centrada en este conflicto. No sólo va mostrarnos a un rey que puede superar sus problemas personales sino que va a poner en el centro del relato la capacidad de construir vínculos empáticos que tiene la radio y cómo estos contribuyen a la formación de una nación. Mientras el Rey finalmente habla, de manera más o menos fluida, se ilustra la profundidad con que la radio penetra en la vida íntima de las personas: acercando, conmoviendo, integrando, haciendo comunidad.

Breves escenas muestran personas y ámbitos diversos unidas por la voz temblorosa del Rey anunciando lo más terrible: el inicio de la segunda guerra mundial. En toda esta secuencia final la radio y el cine parecen comprometerse en construir un suspenso dramático: hacen que el espectador centre su atención en la dimensión individual de los desafíos que enfrenta el Rey para sorprenderlo con el sentido político del contenido del discurso. 
En muchos sentidos esta película puede ser pensada mucho más allá de los problemas individuales de un Rey. Recuerda en muchos momentos a aquellas líneas magistrales de Bertolt Brecht a propósito de la radio:

"Deseo vivamente que esta burguesía, además de haber inventado la radio, invente otra cosa: un invento que haga posible establecer de una vez por todas lo que se puede transmitir por radio. Generaciones posteriores tendrían entonces la oportunidad de ver asombradas cómo una casta, a la vez que haciendo posible decir a todo el globo terráqueo lo que tenía que decir hizo posible también que el globo terráqueo viera que no tenía nada que decir. Un hombre que tiene algo que decir y no encuentra oyentes, está en una mala situación. Pero todavía están peor los oyentes que no encuentran quién tenga algo que decirles." (Bertolt Brecht, 1932)

"Para subir los números debes sacarles lo que quieres, no tener miedo a interrumpirlos o callarlos."

Con esta frase un joven radionauta instruye a una adolescente en el uso de una grabadora de audio portátil. En la oscuridad de la noche, recorren juntos los alrededores del club del pueblo y hacen preguntas a las vecinas y vecinos que deambulan por el lugar. La secuencia presenta una primera tensión entre el periodista y la aprendiz: ¿cuánto y cómo es pertinente meternos en la vida privada de las personas para generar contenidos para la radio? Es uno de los tramos iniciales de The Vast of Night (Andrew Patterson, 2019), una reciente película que narra la historia de un joven locutor de una radio local y una estudiante secundaria y operadora de la central telefónica del lugar. 
La historia, ambientada en la década del cincuenta, transcurre a lo largo de una noche en Cayuga, un pequeño pueblo de Nuevo México. Aunque la trama principal conduce hacia otro rumbo, hay muchos guiños a la radio y la práctica periodística dignos de revisar.

De la representación de la radio que hace la película lo más interesante es esa posibilidad entre lo técnico y lo mágico de enlazar mundos privados y hacer que la vida de las personas se vuelva testimonio público. La película reivindica el lugar de la radio como espacio para que se exprese la voz de aquellos que a menudo no son escuchados.

Mientras cubre su turno nocturno en la central telefónica, Fay descubre un sonido extraño en una de las líneas. Inicia una pesquisa para descubrir de qué se trata y entonces contacta con Everett su joven amigo periodista, que se encuentra haciendo una transmisión en vivo en WOTW, la radio del pueblo. Por causalidad el extraño sonido ha quedado grabado así que deciden reproducirlo nuevamente al aire e inician una encuesta pública para que la audiencia diga si reconoce el extraño sonido.

Un hombre anónimo que se hace llamar Billy se conecta con la radio, a través de la centralita, y cuenta una historia asociada con aquel sonido extraño. Es su propia historia, de lo que escuchó y vivió. Según los dichos de Billy el misterio empieza a asociarse con el fenómeno OVNI. En un momento de la conversación, el locutor duda de lo que está escuchando e intenta chequear la información con el oyente en línea:

- Billy debo preguntarte por qué nos cuentas esto? Esto nos meterá en problemas?

- Supongo que te lo cuento porque estoy enfermo. $Y$ estoy viejo. $Y$ nadie nos escucha. Y quiero que la gente sepa lo que hicimos por ellos. 
- ¿Por qué crees que nadie te escucha?

- Creo que en parte es porque soy negro.

El locutor de radio reflexiona y unos instantes después dice: Nunca nos había llamado una persona negra antes.

Este diálogo procesado tecnológicamente de manera doble (por la central telefónica y la radio) dispara la trama de la película hacia una investigación que Fay y Everett realizarán esa misma madrugada. El teléfono y la radio son puestos como espacios de conexión que promueven la comunicación, el descubrimiento y el conocimiento. Donde la voz de cualquier puede ser escuchada. Recuerda también a ese modelo de radio que Brecht imaginó:

"La radio sería el más fabuloso aparato de comunicación imaginable de la vida pública, un sistema de canalización fantástico, es decir, lo sería si supiera no solamente transmitir, sino también recibir, por tanto, no solamente oír al radioescucha, sino también hacerle hablar, y no aislarle, sino ponerse en comunicación con él. La radiodifusión debería en consecuencia apartarse de quienes la abastecen y constituir a los oyentes en abastecedores." (Bertolt Brecht, 1932) ${ }^{v}$

En este sentido brechtiano The Vast of Night tiene conciencia de radio. De hecho el trabajo de la banda sonora es uno de sus aspectos destacables: el sentido de la audición es interpelado constantemente en primer plano. Primero porque la edición de sonido está delicadamente trabajada. Pero además hay un refuerzo visual al respecto que hace sospechar de una intención notoria para que la película sea más bien escuchada antes que vista. Como si hubiésemos encontrado unas cintas sonoras viejas que nos cuentan esa historia.

Dos cuestiones al respecto. En primer lugar, como la historia transcurre de madrugada la mayoría de las escenas son muy oscuras, están muy sutilmente 
iluminadas virando casi todos los momentos a la penumbra y jugando con las sombras y minúsculos destellos de luz. Pero además, en varios momentos, la intención de suspender el sentido de la vista se pone completamente de manifiesto: la pantalla se pone negra y sólo es posible escuchar los diálogos de los protagonistas. Como si todos los espectadores del film fuésemos en ese momento escuchas del programa de radio a través del cual se intenta seguir la pista de un sonido extraño.

En un pasaje de la entrevista con Billy, Everett intenta tener más información sobre esos sonidos extraños que son señales. Quiere saber de qué tipo de señales está hablando. Y Billy responde:

- Nos dijo que es algo que habla y luego desaparece. Algo muy alto que no podemos ver.

Hablaba de OVNIS. Pero quizá también hablaba de la radio. Al menos de esa posibilidad primera de comunicarnos a la distancia, de crear comunidad a la distancia sorteando el impedimento de lo físico. Una comunidad que se escucha y se reconoce.

En este recorte arbitrario de películas que (no) hablan sobre la radio, hemos podido, sin embargo, crear de alguna esa comunidad que nos muestra con perfecta normalidad cómo la radio puede ser, al mismo tiempo, cosa de mujeres en peligro, fantasmas, reyes, extraterrestres, oficiales de policía, jóvenes tecnófilos, negros silenciados, prófugos, gobernadores, cantantes, artistas, perfectos desconocidos y rutilantes locutores. Una comunidad capaz de conectarse al ritmo inconfundible del tambor tribal y proyectar un eterno resplandor de sonidos y silencios para ser escuchados más allá y hacernos sentir que nunca estamos solos mientras esté la radio. 


\section{Algunas películas sobre la radio}

\section{The Unsuspected (1947)}

Sin sombra de sospecha

Director: Michael Curtiz

Protagonistas: Claude Rains, Joan Caulfield, Audrey Totter

Michael Curtiz dirige en 1947 una película sobre un criminólogo que presenta un importante programa de radio y se ve envuelto en un caso muy similar a los que acoge día tras día en su espacio radiofónico.

\section{Historias de la radio (1955)}

Director: José Luis Sáenz de Heredia

Protagonistas: Francisco Rabal, Margarita Andrey, José Isbert

Esta película española cuenta tres historias cruzadas protagonizadas por extravagantes personajes con algo en común: la radio. Un concurso radiofónico actúa como nexo de unión entre ellos.

\section{Play Misty for Me (1971)}

Escalofrío en la noche

Director: Clint Eastwood

Protagonistas: Clint Eastwood, Jessica Walter, Donna Mills

Clint Eastwood interpreta a un popular locutor de radio que se cita con una misteriosa mujer que no deja de llamar a su programa. Para él es sólo una 
aventura, pero ella siente una atracción enfermiza hacia él que la llevará a acosarlo de forma violenta

\section{Solos en la madrugada (1978)}

Director: José Luis Garci

Protagonistas: José Sacristán, Fiorella Faltoyano, Emma Cohen

En 1977, el locutor de radio José Miguel García Carande recibe el premio Carrusel por "Solos en la madrugada", un programa nocturno de gran audiencia. José Miguel está atravesando una grave crisis sentimental, como consecuencia de la separación de su mujer, y rechaza un bien renumerado puesto en la BBC porque no habla inglés y quiere estar en España para vivir de cerca el proceso de la transición democrática del país.

\section{Radio Days (1987)}

Dias de radio

Director: Woody Allen

Protagonistas: Mia Farrow, Dianne Wiest, Mike Starr

Woody Allen redacta con fotogramas una maravillosa carta de amor a la radio, estrenando en 1987 una película ambientada en los orígenes del medio en los años 40. La vida de todos sus personajes giran en torno al transistor, que actúa como consuelo, entretenimiento o informador.

\section{Good Morning, Vietnam (1987)}

Buenos días Vietnam

Director: Barry Levinson

Protagonistas: Robin Williams, Forest Whitaker, Tom. T. Tran 
Vietnam. 1965. Un pinchadiscos de la radio, Adrian Cronauer, es enviado a Saigón para trabajar en la emisora del ejército norteamericano. En contraste con sus aburridos antecesores, Cronauer es pura dinamita: sus comentarios irreverentes, tacos, improperios y sus críticas al vicepresidente le hacen ganarse el aprecio de las tropas. Sin embargo, su superior, el teniente Hauk, no es de la misma opinión.

\section{Talk Radio (1988)}

La radio ataca

Director: Oliver Stone

Protagonistas: Eric Bogosian, Ellen Greene, Leslie Hope

Barry Champlain es un cínico y cruel locutor de un programa de radio nocturno de gran audiencia en Dallas. Es una persona muy voluble: unas veces, simpático, pero otras, punzante y odioso. Llega incluso a recibir amenazas por la claridad y contundencia con que expresa sus opiniones.

\section{Pump Up the Volume (1990)}

Suban el volumen

Director: Allan Moyle

Protagonistas: Christian Slater, Samantha Mathis, Anthony Lucero

Mark (Christian Slater) es un joven y tímido joven neoyorquino que, al trasladarse su familia de su ciudad natal a Arizona, no logra adaptarse a las conservadoras reglas del colegio local, y decide montar sin el conocimiento de nadie una radio nocturna pirata. Con el micrófono como arma, el joven comienza a ejercer una influencia en los estudiantes, a los que incita a la rebeldía. 


\section{The Fisher King (1991)}

Pescador de ilusiones

Director: Terry Gilliam

Protagonistas: Jeff Bridges, Robin Williams, Adam Bryant

En la imponente Nueva York, Jack Lucas (Jeff Bridges), un famoso locutor de radio caído en desgracia, y Parry (Robin Williams), un enajenado profesor de historia, emprenden la búsqueda del Santo Grial.

\section{En el aire (1995)}

Director: Juan Carlos de Llaca

Protagonistas: Daniel Giménez Cacho, Dolores Heredia, Damián Alcázar

Alberto es disc-jockey en "Radio Púrpura", una estación dedicada a transmitir música de los sesenta. El recuerdo de Laura, su ex-esposa, y la nostalgia por sus locuras juveniles no permiten que Alberto disfrute el presente junto a Ana. Pero el tiempo ha pasado y Alberto tiene que aprender a reconciliarse con sus "fantasmas" y a perdonarse las equivocaciones.

\section{Private Parts (1997)}

Partes privadas

Director: Betty Thomas

Protagonistas: Howard Stern, Mary McCormack, Robin Quivers

El locutor más célebre de la radio norteamericana se interpreta a sí mismo en este filme que relata la historia de su éxito. Howard Srtern, un hombre obsesionado con el sexo, hace un programa de entrevistas dinámico, irreverente, divertido y trepidante. 


\section{Radiofreccia (1998)}

Director: Luciano Ligabue

Protagonistas: Stefano Accorsi, Luciano Federico, Alessio Modica

Cinco amigos son muy aficionados a la música, pero ellos viven en un pequeño pueblo del norte de Italia y pasan la mayor parte de sus días en el bar local. Deciden crear una radio independiente que pronto se convierte en la voz de una generación. Cuando uno de ellos muere de una sobredosis, la radio tomará su nombre.

\section{Frequency (2000)}

Desafío al tiempo

Director: Gregory Hoblit

Protagonistas: Dennis Quaid, Jim Caviezel, Shawn Doyle

John (James Caviezel) vive obsesionado con la muerte de su padre, un bombero (Dennis Quaid), que pereció 30 años antes durante un incendio. Un día, un extraño fenómeno meteorológico le permite hablar con él, a través de un viejo equipo de radioaficionado con el que se comunica con el pasado: John informa a su padre de los errores cometidos en aquel incendio y así evita su muerte. Sin embargo, de este vuelco del destino se derivarán otros trágicos acontecimientos.

\section{O Brother, Where Art Thou? (2000)}

¿Dónde estás hermano?

Directors: Joel Coen, Ethan Coen (uncredited)

Protagonistas: George Clooney, John Turturro, Tim Blake Nelson 
Everest Ulyssess McGill (Clooney), un delincuente de poca monta, es detenido y condenado a trabajos forzados en el estado de Mississippi. Sus dificultades para adaptarse a la estricta disciplina de la prisión lo llevan a elaborar un plan de fuga.

\section{Good Night, and Good Luck (2005)}

Buenas noches, y buena suerte

Director: George Clooney

Protagonistas: David Strathairn, George Clooney, Patricia Clarkson

Ambientada en 1953, narra el enfrentamiento real que, en defensa del periodismo independiente, mantuvieron el famoso periodista y presentador de la CBS Edward R. Murrow (David Strathairn) y su productor Fred Friendly (George Clooney) contra el poderoso senador anticomunista Joseph McCarthy, hecho que determinó el final de la "caza de brujas"

\section{A Prairie Home Companion (2006)}

El último show

Director: Robert Altman

Protagonistas: Lily Tomlin, Meryl Streep, Woody Harrelson

La radio americana emite desde 1974 un magazine radiofónico para toda la familia. Las cosas se tuercen cuando presentador e invitados se enteran de que en esos momentos están realizando su último programa. $Y$ es que la radio también puede ser cruel en la que es, ni más ni menos, que la última película del legendario Robert Altman. 


\section{The Boat That Rocked (2009)}

Radio pirata

Director: Richard Curtis

Protagonistas: Philip Seymour Hoffman, Bill Nighy, Nick Frost

Basada en hechos reales, el film narra las peripecias de una emisora de radio pirata que emitía durante los años 60 en Reino Unido desde el mar del Norte. Su objetivo era propagar la música rock entre los británicos, tan sedientos de música movidita que le dieron audiencias millonarias (literalmente más de la mitad del país la oía).

\section{Radio: Love on Air (2009)}

El amor en el aire

Director: Ishaan Trivedi (as Ishan Trivedi)

Protagonistas: Himesh Reshammiya, Shenaz Treasury, Sonal Sehgal

Esta comedia dramática de la India cuanta la historia de un DJ de radio popular quien continúa enamorado de su ex esposa y es obligado a sostener un nuevo romance para mejorar su audiencia.

\section{The King's Speech (2010)}

El discurso del rey

Director: Tom Hooper

Protagonistas: Colin Firth, Geoffrey Rush, Helena Bonham Carter

La oscarizada película dirigida por Tom Hooper y protagonizada por Colin Firth abordaba el tragicómico tartamudeo de un monarca como un problema de estado que atentaba contra su imagen y autoridad. La radio está presente en este caso con connotaciones negativas: el micrófono es el monstruo bajo la 
cama del personaje interpretado por Firth, que debía dar un importante discurso sin trastabillar dialécticamente.

\section{La Maison de la radio}

La casa de la radio (2013)

Director: Nicolas Philibert

Protagonistas: Jean-François Achilli, Evelyne Adam, Jean-Claude Ameisen Inmersión en Radio France para descubrir lo que no se suele ver a primera vista: los misterios y entresijos de un medio cuya materia, sonido, permanece invisible.

\section{The Vast of Night (2019)}

Director: Andrew Patterson

Protagonistas: Sierra McCormick, Jake Horowitz, Gail Cronauer

Nuevo México, Estados Unidos. Dos trabajadores de una radio local, un operador de radio y un pinchadiscos, descubren en la década de los años 50 una frecuencia que podría cambiar su vida y la de toda la humanidad para siempre.

' Mc LUHAN, Marshall. Comprender los medios de comunicación. Ediciones Paidós, Buenos Aires, 1994.

ii Mc LUHAN, Marshall. Comprender los medios de comunicación. Ediciones Paidós, Buenos Aires, 1994.

iii Mc LUHAN, Marshall. Comprender los medios de comunicación. Ediciones Paidós, Buenos Aires, 1994. 
iv BRECHT, Bertolt, Teorías de la radio, en El compromiso en Literatura y Arte. Editorial Península, Barcelona, 1973.

${ }^{\vee}$ BRECHT, Bertolt, Teorías de la radio, en El compromiso en Literatura y Arte.

Editorial Península, Barcelona, 1973. 